\title{
Respiratory Care Considerations in the Childhood Cancer Patient
}

\author{
Lama Elbahlawan MD, K Jason Rains RRT MAEd, and Dennis C Stokes MD MPH
}

\author{
Introduction \\ Historical Perspective \\ Lung, Airway, and Chest-Wall Involvement in Primary Malignancy \\ Opportunistic and Usual Respiratory Infections in the Childhood Cancer \\ Patient \\ Acute Lung Injury From Chemotherapy and Radiation \\ Later Cardiopulmonary Complications of Cancer Therapy \\ Lung and Cardiac Function in Adult Childhood Cancer Survivors \\ Exercise \\ Pulmonary Complications of Hematopoietic Stem Cell Transplantation \\ Infectious Complications \\ Non-Infectious Complications \\ Respiratory Therapy Treatments and Interventions in the Childhood \\ Cancer Patient \\ Aerosol Therapies \\ Noninvasive Ventilation \\ Positive-Pressure Ventilation \\ Tracheostomy \\ Prolonged Mechanical Ventilation \\ Lung Transplantation
}

\begin{abstract}
This article reviews the common pulmonary complications seen in the pediatric oncology population and our approach to diagnosis, management, and therapy considerations in this specialized population, including patients receiving chemotherapy, radiation, and hematopoietic stem cell transplantation. Although infections cause the most significant complications in this population, non-infectious complications, including acute lung injury from chemotherapy or radiation, idiopathic interstitial pneumonia, diffuse alveolar hemorrhage, bronchiolitis obliterans, and cryptogenic organizing pneumonia, also occur commonly. With improvements in survival of childhood cancer, there are now a growing number of adults who are childhood cancer survivors who may be encountered by therapists in adult hospitals. We also review the growing literature on the emerging late pulmonary findings in these adult childhood cancer survivors. Key words: childhood cancer; chemotherapy; radiation; hematopoietic stem cell transplantation; interstitial pneumonia; pulmonary hemorrhage; bronchiolitis oblterans; pnemonia. [Respir Care 2017;62(6):765-775. @ 2017 Daedalus Enterprises]
\end{abstract}

\section{Introduction}

Childhood cancer therapy is associated with a wide variety of pulmonary complications during therapy. Most care of children with cancer is done in specialized cancer centers, so most respiratory therapists may not be involved in the care of these complex patients. This article reviews the common pulmonary complications seen in our large children's cancer center and our approach to diagnosis, management, and therapy considerations in this specialized population. With improvements in survival of childhood cancer, there is now a growing number of adults who 


\section{Respiratory Care Considerations in Childhood Cancer}

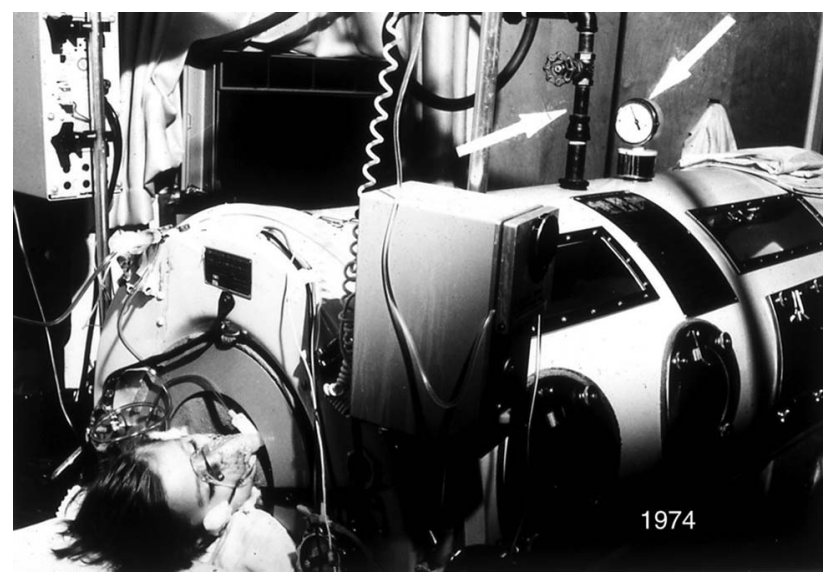

Fig. 1. Continuous negative pressure for Pneumocystis pneumonia.

are childhood cancer survivors who may be encountered by therapists in adult hospitals. Therefore, we also review the growing literature on the late pulmonary findings in these adult childhood cancer survivors.

\section{Historical Perspective}

In the 1970s, large numbers of children began to survive their primary malignancy, only to die with infectious complications, including Pneumocystis jirovecii (formally carinii) pneumonia. Initially, there was great reluctance to intubate cancer patients due to fear of worse pulmonary complications. Drs Sam Sanyal and Walter Hughes at St Jude Children's Research Hospital pioneered the use of negative pressure to avoid intubation and saved many $P$. jirovecii pneumonia patients during that period ${ }^{1}$ (Fig. 1). With the discovery of effective $P$. jirovecii pneumonia prophylaxis in 1975 using trimethoprim-sulfamethoxazole, this infection ceased to be a major cause of mortality. ${ }^{2}$ However, with more intensive chemotherapy and radiation reg-

Dr Elbahlawan is affiliated with the Division of Critical Care, Department of Pediatric Medicine, and Mr Rains is affiliated with the Respiratory Therapy Department and Intensive Care Unit, St Jude Children's Research Hospital, Memphis, Tennessee. Dr Stokes is affiliated with the Division of Pulmonary and Sleep Medicine, Department of Pediatrics, University of Tennessee Health Science Center, Le Bonheur Children's Hospital, and St Jude Children's Research Hospital, Memphis, Tennessee.

The authors have disclosed no conflicts of interest.

Dr Stokes presented a version of this paper at the 55th RESPIRATORY CARE Journal Conference, "Pediatric Respiratory Care," held June 10-11, 2016, in St Petersburg, Florida.

Correspondence: Dennis C Stokes MD MPH, University of Tennessee Health Science Center College of Medicine, 49 North Dunlap, Memphis, TN 38103. E-mail: dstokes4@uthsc.edu.

DOI: $10.4187 /$ respcare. 05223 imens, fungal and viral infections, such as Aspergillus, cytomegalovirus, and varicella zoster, emerged as the primary pulmonary infectious pathogens in the 1980s. ${ }^{3,4} \mathrm{Al}-$ though the prognosis for pediatric cancer and hematopoietic stem cell (bone marrow) transplant patients was poor during this early period, later advances in antifungal and antiviral therapy and supportive pediatric critical care for cancer patients has significantly improved survival since the 1990s. ${ }^{5-7}$ With improved survival, we have seen the development of more chronic lung injury syndromes in oncology patients who require long-term respiratory support, including tracheostomy and prolonged mechanical ventilation.

\section{Lung, Airway, and Chest-Wall Involvement in Primary Malignancy}

Although primary lung tumors are rare in childhood, primary and secondary tumor involvement can cause significant problems during initial therapy for childhood cancer. These problems include airway obstruction from large mediastinal tumors or lymph nodes. The management of large mediastinal tumors or malignant lymph nodes may involve the respiratory therapist, since simple sedation can lead to life-threatening airway obstruction without careful planning. ${ }^{8}$ In addition, the chest wall may be involved in primary malignancies, and resection of ribs and chest wall can contribute to respiratory complications. The most common primary pediatric lung tumors include pleuropulmonary blastoma (chest masses) and carcinoid tumors (endobronchial obstruction).$^{9}$ Large malignant pleural effusions can also complicate initial management of childhood cancers and may require chest tube insertion or tapping for diagnostic purposes or relief of respiratory distress. The lung is more likely to be involved with metastatic disease with pediatric tumors, particularly for malignancies such as Wilms' tumor; osteosarcomas; other sarcomas, such as Ewing's sarcoma and rhabdomyosarcoma; and hepatoblastoma. Surgical resection of these metastatic lesions can contribute to reduced lung function, particularly after resection of multiple lesions. ${ }^{10}$

\section{Opportunistic and Usual Respiratory Infections in the Childhood Cancer Patient}

Some common pulmonary pathogens are listed in Table 1. The term opportunistic infection usually refers to organisms that typically are seen primarily in patients with a compromised immune status (eg, neutropenia or depressed T- or B-cell immunity). Infections such as cytomegalovirus, Pneumocystis, and fungi, such as Candida and Aspergillus, are usually seen in patients with both primary and acquired immunodeficiency states, such as during cancer treatment. In addition, cancer patients can also be infected 


\section{Respiratory Care Considerations in Childhood Cancer}

Table 1. Typical Pulmonary Pathogens Associated With Acquired Immunodeficiency States

\begin{tabular}{|c|c|c|c|}
\hline Status & Bacterial & Fungal & Viral/Protozoal/Other \\
\hline \multicolumn{4}{|l|}{ Neutropenia } \\
\hline Chronic & $\begin{array}{l}\text { Haemophilus influenzae, Streptococcus } \\
\text { pneumoniae, Staphylococcus aureus, } \\
\text { Klebsiella species }\end{array}$ & NA & NA \\
\hline Acute & S. aureus & NA & NA \\
\hline $\begin{array}{l}\text { Immunosuppressive } \\
\text { therapy }\end{array}$ & $\begin{array}{l}\text { S. aureus, Listeria species, } \\
\text { Mycobacterium tuberculosis }\end{array}$ & $\begin{array}{l}\text { Aspergillus species, Mucor } \\
\text { species, Histoplasma } \\
\text { species }\end{array}$ & $\begin{array}{l}\text { Cytomegalovirus, Pneumocystis jirovecii, } \\
\text { VZV, Toxoplasma species, herpes } \\
\text { simplex virus, Cryptococcus species }\end{array}$ \\
\hline \multicolumn{4}{|l|}{ Bone marrow transplant } \\
\hline Early $(<30 \mathrm{~d})$ & $\begin{array}{l}\text { Pseudomonas species, other Gram- } \\
\text { negative and Gram-positive species }\end{array}$ & Candida species & NA \\
\hline Late $(>30 \mathrm{~d})$ & S. aureus & Aspergillus species & $\begin{array}{l}\text { Cytomegalovirus, Toxoplasma species, } \\
\text { VZV, P. jirovecii, Epstein-Barr virus, } \\
\text { adenovirus }\end{array}$ \\
\hline Very late $(>100 \mathrm{~d})$ & $\begin{array}{l}\text { Encapsulated Gram-positive } \\
\quad(\text { H. influenzae, S. pneumoniae })\end{array}$ & NA & $\mathrm{VZV}$ \\
\hline \multicolumn{4}{|l|}{$\begin{array}{l}\text { Data from Reference } 4 . \\
\text { NA = not applicable } \\
\text { VZV = varicella-zoster }\end{array}$} \\
\hline
\end{tabular}

with common bacterial and viral respiratory pathogens, such as Staphylococcus aureus, influenza, respiratory syncytial virus (RSV), human metapneumovirus, adenovirus, and varicella zoster, but these common infections can lead to catastrophic pulmonary infection in the immunocompromised population. ${ }^{3,11-14}$ The degree of residual host defense also plays a role in the severity of the lung process, and the phenomenon of worsening lung disease with recovery of immune function following cancer therapy is well described for a number of respiratory pathogens. Many neutropenic children with acute respiratory failure experience worsening of their oxygenation during neutrophil recovery. ${ }^{15}$

Common pulmonary infections in pediatric cancer patients include viral infections like cytomegalovirus. Cytomegalovirus pneumonia can occur as a primary infection in individuals with no evidence of prior infection by serum antibody levels or as reactivation in individuals previously infected. The impact of cytomegalovirus has been mitigated somewhat by aggressive monitoring of early cytomegalovirus disease using molecular detection techniques (polymerase chain reaction titers) and by use of prophylaxis (acyclovir) or treatment with ganciclovir, foscarnet, and galganciclovir. RSV and human metapneumovirus are common causes of severe and prolonged lower respiratory disease in infants and children during cancer therapy and may occur as co-pathogens in association with other respiratory infections, particularly in the bone marrow transplantation patients. Palivizumab administration for patients at risk of RSV infection helps to reduce the risk of severe illness from RSV. Adenovirus is another common respiratory viral pathogen that can cause disseminated disease with lung, liver, and gastrointestinal involvement. Cidofovir or CMX001, a new orally bioavailable lipid conjugate of cidofovir, can be used for treatment. ${ }^{12,16} P$. jirovecii (formerly carinii, now reserved for a similar infection in rats) is one of the fungal pathogens that can still be seen in this population if there is poor adherence with prophylaxis and can lead to a severe infection with hypoxemia and respiratory failure. Other invasive fungal organisms commonly seen in pediatric cancer patients include Aspergillus species (primarily A.fumigatus), Mucor, and Rhizopus. These organisms can cause severe tracheobronchitis, pneumonia, and, in the case of Mucor, devastating direct invasion of pulmonary blood vessels. Diagnosis is usually made by direct examination of tissue obtained by open or needle biopsy. Bronchoscopy/bronchoalveolar lavage (BAL) has historically had a low yield in fungal infections, particularly early in the infection, but the use of galactomannan detection in serum and BAL may be helpful in improving the early detection of Aspergillus. ${ }^{17}$ Because of the difficulty in making a tissue diagnosis, patients often receive prolonged empiric antifungal therapy with oral antifungal agents, such as itraconazole, voriconazole, micafungin, or posaconazole, with amphotericin B reserved for refractory cases. Surgical intervention with removal of pulmonary nodules is sometimes sought when the pulmonary fungal disease is not disseminated. ${ }^{18}$ Candida species are common colonizers of the respiratory tract in cancer patients (particularly with prolonged antibiotic therapy), but primary Candida pneumonia is relatively uncommon. Invasive sepsis and secondary pulmonary involvement is more likely, typically with $C$. albicans and $C$. tropicalis. In endemic areas, fungal organisms, such as histoplasmosis, can 


\section{Respiratory Care Considerations in Childhood Cancer}

also be an important cause of pulmonary involvement in immunocompromised hosts or cause disseminated disease in normal infants. Many patients with histoplasmosis are also referred to St Jude because of concern about hilar adenopathy to rule out malignancy. ${ }^{19}$

\section{Acute Lung Injury From Chemotherapy and Radiation}

Patients receiving radiation involving the lung are likely candidates for acute radiation-induced changes in lung function. Frank radiation pneumonitis occurs in up to $15 \%$ of older patients. With modern radiation dosing and targeting, these acute pulmonary effects of radiation are usually minimized and are able to be managed with supportive care, although radiation remains a significant risk factor for late pulmonary effects. ${ }^{20}$ Several chemotherapy agents (eg, bleomycin and dactinomycin) increase the risk of radiation pneumonia. Adriamycin and actinomycin D are also associated with a recall pneumonia when administered after radiation. Radiation injury may also affect subsequent lung and chest-wall growth. ${ }^{21}$

\section{Later Cardiopulmonary Complications of Cancer Therapy}

Both radiation and chemotherapy are well described as causing both cardiac and pulmonary late effects (Table 2). ${ }^{22-24}$ For cardiac effects, the classic agents associated with late cardiac toxicity are the anthracyclines in a dosedependent manner. A number of chemotherapy agents are associated with late pulmonary injury, including bleomycin, carmustine, lormustine, busulfan, and cyclophosphamide.

\section{Lung and Cardiac Function in Adult Childhood Cancer Survivors}

With improved therapy for childhood malignancy, there is a growing population of childhood cancer survivors, and a significant literature now exists on late effects of childhood cancer therapy. Evidence-based guidelines for riskbased assessment of cardiac and pulmonary outcomes in childhood cancer survivors have been developed. ${ }^{25}$ Studies in this population of survivors from St Jude Children's Research Hospital (St Jude Lifetime Cohort) have documented a wide range of systemic complications, but pulmonary complications are among the most common. ${ }^{26,27}$ For the most common childhood cancer, acute lymphocytic leukemia, the pulmonary outcomes are excellent, since therapy does not generally include drugs with significant pulmonary toxicity. ${ }^{28}$ In the past, therapy for acute lymphocytic leukemia included craniospinal irradiation, and since a portion of the lung is included, some effect on the lung function can be seen. ${ }^{29}$ Other therapies that include chemotherapy agents that affect the lung or radiation are associated with significant late lung function abnormalities. A recent report of 606 childhood cancer survivors from St Jude (median elapsed time from diagnosis of 21.9 y) described pulmonary function abnormalities (49\% with $\mathrm{FEV}_{1}$ and $45 \%$ with FVC lower than the lower limit of normal) with $32 \%$ having restrictive lung defects (total lung capacity $<75 \%$ predicted). ${ }^{27}$ Risk factors for reduced lung function include the volume of lung receiving radiation and elapsed time from diagnosis, as well as age at diagnosis (for FVC and total lung capacity). Abnormal pulmonary function tests were also associated with decreased 6-min walk distance. ${ }^{27}$ As noted, cardiac function is affected by a variety of agents, primarily anthracyclines, that affect cardiac function. Impaired cardiac function can be a significant problem during cancer therapy, particularly when patients have secondary problems with fluid overload, acute infections, ARDS, or respiratory or multisystem failure. Although the major problem with anthracyclines is cardiomyopathy, findings on cardiac echocardiogram suggestive of pulmonary hypertension have also been identified in adult childhood cancer survivors, although the exact mechanism for these changes is still being elucidated. ${ }^{30}$

\section{Exercise}

The effects of cancer therapy on reducing exercise performance are well described in the St Jude Lifetime Cohort study and other follow-up studies. ${ }^{25,27}$ The effects of therapy on exercise performance are multifactorial and include reduced cardiopulmonary function, as well as decreased muscle strength. Generalized muscle weakness is common during cancer therapy, but how this relates to acute pulmonary complications, such as pneumonia or atelectasis, has not been studied. Some evidence suggests that exercise interventions can improve cardiopulmonary fitness, strength and flexibility, and physical function in this population. ${ }^{31}$ In cancer survivors, $18.1 \%$ reported deficits in physical performance, whereas $10.5 \%$ reported deficits in emotional health, both significantly impacting health-related quality of life. ${ }^{32}$

\section{Pulmonary Complications of Hematopoietic Stem Cell Transplantation}

Hematopoietic stem cell transplantation is a well-established treatment now for both refractory malignant and non-malignant conditions. There is extensive literature on the diverse pulmonary complications in hematopoietic stem cell transplantation that occur during acute therapy or appear later in hematopoietic stem cell transplantation survivors. Patients undergoing hematopoietic stem cell 


\section{Respiratory Care Considerations in Childhood Cancer}

Table 2. Treatment Exposure-Based Risk Factors for Pulmonary Late Effects in Survivors of Childhood Cancer

\begin{tabular}{|c|c|c|}
\hline Treatment Exposures & Potential Late Effects & Risk Factors \\
\hline Radiation & $\begin{array}{l}\text { Pulmonary toxicity } \\
\text { Pulmonary fibrosis } \\
\text { Interstitial pneumonitis } \\
\text { Restrictive lung disease } \\
\text { Obstructive lung disease }\end{array}$ & $\begin{array}{l}\text { Host factors } \\
\text { Younger age at irradiation } \\
\text { Treatment factors } \\
\text { Radiation dose } \geq 15 \text { Gy } \\
\text { Chest radiation combined with TBI } \\
\text { Radiation combined with } \\
\text { Bleomycin } \\
\text { BCNU } \\
\text { CCNU } \\
\text { Radiomimetic chemotherapy (eg, doxorubicin, dactinomycin) } \\
\text { Medical conditions } \\
\text { Atopic history } \\
\text { Health behaviors } \\
\text { Smoking }\end{array}$ \\
\hline $\begin{array}{l}\text { Alkylating agents } \\
\text { Busulfan } \\
\text { BCNU }\end{array}$ & Pulmonary fibrosis & $\begin{array}{l}\text { Treatment factors } \\
\text { Higher cumulative doses }(>500 \mathrm{mg}) \text { combined with radiation } \\
\text { Medical conditions } \\
\text { Atopic history }\end{array}$ \\
\hline $\mathrm{CCNU}$ & & $\begin{array}{l}\text { Health behaviors } \\
\text { Smoking }\end{array}$ \\
\hline Bleomycin & $\begin{array}{l}\text { Pulmonary toxicity } \\
\text { Interstitial pneumonitis } \\
\text { Pulmonary fibrosis } \\
\text { ARDS (very rare) }\end{array}$ & $\begin{array}{l}\text { Host factors } \\
\text { Younger age at treatment } \\
\text { Treatment factors } \\
\text { Higher cumulative doses }\left(\geq 400 \text { units } / \mathrm{m}^{2}\right) \text { combined with } \\
\text { Chest irradiation } \\
\text { Busulfan } \\
\text { BCNU } \\
\text { CCNU } \\
\text { Medical conditions } \\
\text { Renal dysfunction } \\
\text { High-dose oxygen support such as during general anesthesia } \\
\text { Health behavior } \\
\text { Smoking }\end{array}$ \\
\hline HSCT with any history of chronic GVHD & $\begin{array}{l}\text { Pulmonary toxicity } \\
\text { BO } \\
\text { BOOP } \\
\text { IPS } \\
\text { Restrictive lung disease } \\
\text { Obstructive lung disease }\end{array}$ & $\begin{array}{l}\text { Host factors } \\
\text { Younger age at HSCT } \\
\text { Treatment factors } \\
\text { Chest radiation } \\
\text { TBI } \\
\text { High-dose chemotherapy } \\
\text { Pulmonary toxic chemotherapy } \\
\text { Bleomycin } \\
\text { Busulfan } \\
\text { BCNU } \\
\text { CCNU }\end{array}$ \\
\hline $\begin{array}{l}\text { Surgery } \\
\text { Pulmonary lobectomy } \\
\text { Pulmonary metastasectomy } \\
\text { Pulmonary wedge resection }\end{array}$ & Pulmonary dysfunction & $\begin{array}{l}\text { Treatment factors } \\
\text { Combined with pulmonary toxicity therapy } \\
\text { Bleomycin } \\
\text { Busulfan } \\
\text { BCNU } \\
\text { CCNU } \\
\text { Medical conditions } \\
\text { Atopic history } \\
\text { Health behaviors } \\
\text { Smoking }\end{array}$ \\
\hline $\begin{array}{l}\text { TBI = total body irradiation } \\
\text { Gy }=\text { Gray } \\
\text { BCNU = carmustine } \\
\text { CCNU = lomustine } \\
\text { GVHD = graft-vs-host disease } \\
\text { HSCT = hematopoietic stem cell transplant } \\
\text { BO = bronchiolitis obliterans } \\
\text { BOOP = bronchiolitis obliterans organizing pneumoni } \\
\text { IPS = idiopathic pneumonia syndrome }\end{array}$ & & \\
\hline
\end{tabular}




\section{Respiratory Care Considerations in Childhood Cancer}

Timeline of Non-Infectious Pulmonary Complications

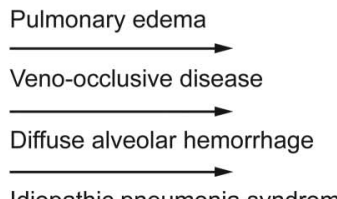

Idiopathic pneumonia syndrome

Graft-vs-host disease (acute and chronic)

Interstitial lung disease

Post-transport lymphoproliferative disease

Bronchiolitis obliterans

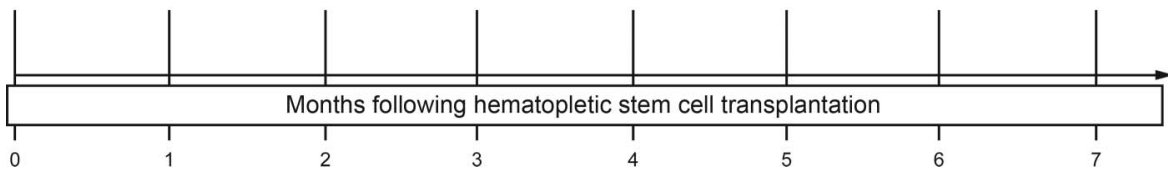

Fig. 2. Timeline of non-infectious complications in organ and hematopoietic stem cell transplantation transplantation. From Reference 4 , with permission.

transplantation have generally been pretreated with chemotherapy or radiation for their primary disease as well as receiving immunosuppressive regimens to prepare for the new bone marrow cells. These treatments lead to injury to the lung and altered lung function before transplant. The increased risk associated with low lung function before hematopoietic stem cell transplantation was demonstrated by Srinivasan et al, ${ }^{33}$ who examined lung function in a large cohort of 410 hematopoietic stem cell transplantation subjects. In this study, $42 \%$ developed pulmonary complications, and lower lung function at baseline before transplant significantly increased the risk of transplant. T cell depletion of the hematopoietic stem cell transplantation graft, acute grade 3-4 graft-versus-host disease and chronic graft-versus-host disease increased the risk of pulmonary complications, and pulmonary complications resulted in a 2.8-fold increased risk of mortality. ${ }^{33}$

\section{Infectious Complications}

Pulmonary infections remain a major cause of morbidity and mortality in hematopoietic stem cell transplantation patients, and the types of infectious complications are usefully classified according to the time period after transplant (Table 1). ${ }^{4}$

\section{Non-Infectious Complications}

Non-infectious complications in hematopoietic stem cell transplantation include severe mucositis and pulmonary edema (due to fluid overload, cardiac compromise, or renal toxicity) (Fig. 2). Engraftment initially can be associ- ated with pulmonary edema and may lead to hypoxia secondary to inflammatory response. Idiopathic pneumonia syndrome is characterized by dyspnea; cough; hypoxemia, with no detection of infectious agent on BAL; and restrictive pulmonary function changes. ${ }^{34}$ Immunosuppressive therapy with corticosteroids and anti-tumor necrosis factor agents like etanercept are usually mainstays of treatment. Diffuse alveolar hemorrhage (DAH) is a less common complication but historically has had a very poor prognosis. ${ }^{35}$ If DAH is associated with multi-organ failure, mortality can be $>80 \%$. The diagnosis of DAH is generally made by BAL with increasingly hemorrhagic lavage with each BAL aliquot and exclusion of underlying pulmonary infection as a cause of hemorrhage. Treatment includes using corticosteroids, correction of coagulopathy and thrombocytopenia, administration of aminocaproic acid to stabilize clots, and judicious use of higher PEEP on mechanical ventilation. Pulmonary and hepatic veno-occlusive disease presents with pulmonary hypertension, signs of right-heart failure, and pulmonary infiltrates. It is characterized by obstruction of the small veins and venules secondary to fibrosis. ${ }^{36}$ Obliterative bronchiolitis is the most common late pulmonary complication of hematopoietic stem cell transplantation and is usually associated with other manifestations of graft-versus-host disease, such as skin or hepatic involvement. Post-transplant infections, including viral infections (like adenoviral infection) may increase the risk of obliterative bronchiolitis. The diagnosis of obliterative bronchiolitis is now usually made by a combination of fixed airway obstruction (for patients old enough to do pulmonary function tests) and high-resolution CT with inspiratory/expiratory views showing areas 


\section{Respiratory Care Considerations in Childhood Cancer}

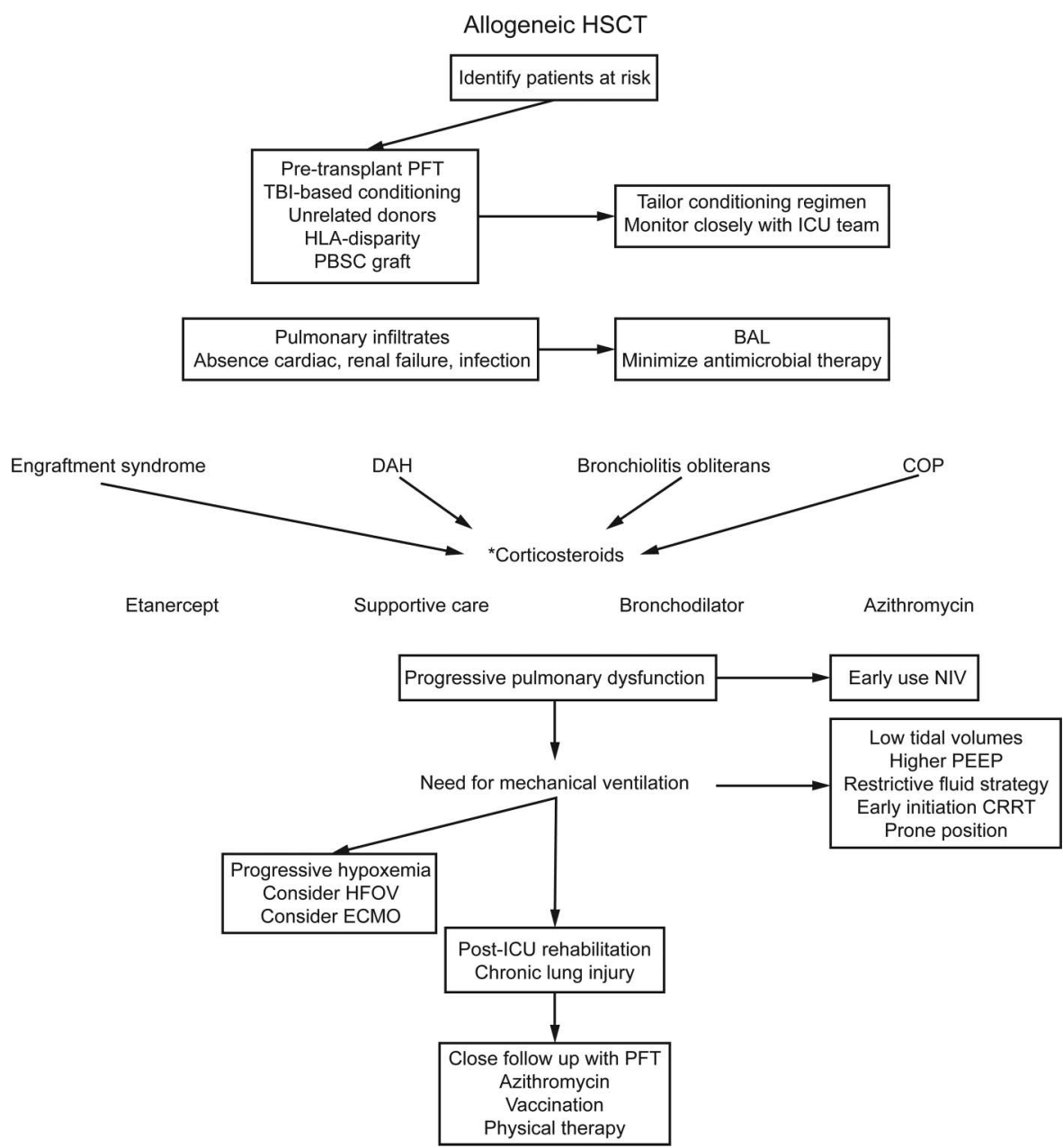

Fig. 3. Approach to a patient with evolving pulmonary dysfunction following hematopoietic stem cell transplantation (HSCT). ${ }^{*} \mathrm{~A}$ short course of corticosteroids without taper is suggested for engraftment syndrome. Doses of $2 \mathrm{mg} / \mathrm{kg} / \mathrm{d}$ may be used for diffuse alveolar hemorrhage (DAH). Inhaled steroids are recommended for bronchiolitis obliterans. A prolonged course of steroids may be necessary for cryptogenic organizing pneumonia (COP). PFT = pulmonary function test, TBI = total body irradiation, HLA = human leukocyte antigen, PBSC = peripheral blood stem cell, BAL $=$ bronchoalveolar lavage, NIV = noninvasive ventilation, CRRT = continuous renal replacement therapy, HFOV = high-frequency ventilation, ECMO = extracorporeal membrane oxygenation. From Reference 46, with permission.

of patchy hyperinflation, alternating with areas of increased density (so-called mosaic pattern). ${ }^{37,38}$ Cryptogenic organizing pneumonia, formerly known as BOOP (bronchiolitis obliterans-organizing pneumonia) is another late complication of hematopoietic stem cell transplantation and differs from obliterative bronchiolitis in biopsy appearance (with areas of organizing pneumonia, as the name suggests) with features of obliterative bronchiolitis, restrictive lung defects rather than obstructive, and improvement with systemic corticosteroids. ${ }^{39}$ Pulmonary alveolar proteinosis has been described as a secondary complication in some childhood cancers and in hematopoietic stem cell transplantation due to accumulation of surfactant protein in the alveolar space secondary to defective macrophages. The diagnosis is usually made by BAL showing the typical milky white fluid of alveolar proteinosis. ${ }^{40}$ Treatment usu- ally involves the use of granulocyte-macrophage colonystimulating factor.

\section{Respiratory Therapy Treatments and Interventions in the Childhood Cancer Patient}

\section{Aerosol Therapies}

The obstructive lung disease of obliterative bronchiolitis is usually not associated with reversible airway obstruction, but some patients do appear to have a reversible component that may benefit from bronchodilator therapy. The use of so-called FAM therapy (high dose inhaled fluticasone-azithromycin-montelukast) for obliterative bronchiolitis has been reported to improve the need for corticosteroids in some small series, but more research is needed, 


\section{Respiratory Care Considerations in Childhood Cancer}

particularly in the pediatric hematopoietic stem cell transplantation population. ${ }^{41}$ In patients with DAH, administration of activated factor VII has been used in pediatric patients by direct instillation or aerosolization, but more studies are needed because of the potential for adverse events like endotracheal tube obstruction by clot. ${ }^{42}$ The use of inhaled ribavirin in immunocompromised hosts with RSV is controversial, although the greatest benefit appears to be when started early in the course of lower respiratory infection; whether it has a role in the intubated patient with severe RSV pneumonia is unclear. ${ }^{13,43}$ Human metapneumovirus also demonstrates in vitro susceptibility to ribavirin.

\section{Noninvasive Ventilation}

Noninvasive ventilation with CPAP and bi-level positive airway pressure has generally replaced negativepressure ventilation for supportive care of pediatric cancer patients, and many patients have successfully avoided intubation with early use of noninvasive ventilation. ${ }^{44}$ Highfrequency chest oscillation using an external chest shell (Hayek oscillator) is the modern equivalent of the 1970s iron lung and has been used with success in other acute respiratory failure settings, although there is insufficient literature to recommend it at this time. ${ }^{45}$ For cancer patients with increased risk of infection, less invasive approaches may decrease the risk of ventilator-associated pneumonia.

\section{Positive-Pressure Ventilation}

Intubation and positive-pressure ventilation is the procedure of choice for ventilatory support in this population. Current approaches to mechanical ventilation include a protective lung strategy with the use of low tidal volumes and permissive hypercapnia, prone positioning, conservative fluid management, and new modes of conventional ventilation that have improved outcomes in most ICUs providing care for cancer patients. A recent report from our institution emphasized the importance of a team approach, particularly for hematopoietic stem cell transplantation patients, for patients who require mechanical ventilation (Fig. 3). ${ }^{46}$ Other techniques, such as high-frequency oscillation, are usually used as a salvage therapy, and whether the earlier initiation of highfrequency ventilation will improve outcome is still unknown.

\section{Tracheostomy}

As children with cancer survive their complicated acute pulmonary complications, the question of whether to perform a tracheostomy may become an important issue. Tra- cheostomy does not appear to carry a significantly higher risk than in other populations, although children have higher risk of infection with the common bacterial organisms, such as Pseudomonas, that colonize most tracheostomy patients secondary to their immunosuppressed status.

\section{Prolonged Mechanical Ventilation}

Pediatric cancer patients who need support due to severe lung injury or central hypoventilation (brain tumor patients) are candidates for long-term mechanical ventilation, and the same considerations for preparing these patients and families apply as for other populations. ${ }^{47}$ For some patients with poor prognosis from their underlying malignancy, home mechanical ventilation may have different goals for the patient and family, such as allowing a return to home for a period of time in palliative mode.

\section{Lung Transplantation}

For patients with end-stage lung disease due to pulmonary fibrosis or obliterative bronchiolitis or after severe infections, the question of possible lung transplantation may be raised. Because of the shortage of lung donors, patients must generally be in remission. Varying time period requirements that a patient must be in remission before lung transplantation would be considered differ among different lung transplant centers, with the minimum period being 2 years. One review of lung transplantation in pediatric hematopoietic stem cell transplantation patients with end-stage obliterative bronchiolitis reported that the outcome of patients post-lung transplant was comparable with other transplant recipient populations. ${ }^{48}$

\section{REFERENCES}

1. Sanyal SK, Avery TL, Hughes WT, Kumar MA, Harris KS. Management of severe respiratory insufficiency due to Pneumocystis carinii pneumonitis in immunocompromised hosts: the role of continuous negative-pressure ventilation. Am Rev Respir Dis 1977; 116(2):223-231.

2. Hughes WT. Five year absence of Pneumocystis carinii pneumonia in a pediatric oncology center. J Infect Dis 1984;150(2):305306.

3. Stokes DC, Feldman S, Sanyal SK, Mackert PW. Pulmonary function following varicella-zoster pneumonia in children with leukemia. Pediatr Pulmonol 1987;3(4):236-241.

4. Spahr J, Weiner DJ, Stokes DC, Kurland G. Pulmonary disease in the pediatric patient with acquired immunodeficiency states. In: Wilmott R, Boat T, Bush A, Chernick V, Deterding R, Ratjen F, editors. Kendig and Chernick's Disorders of the Respiratory Tract in Children, 8th edition. Philadelphia, Pennsylvania: Elsevier Health Sciences; 2012:899-919.

5. Tamburro RF, Barfield RC, Shaffer ML, Rajasekaran S, Woodard P, Morrison R, et al. Changes in outcomes (1996-2004) for pediatric oncology and hematopoietic stem cell transplant patients requiring invasive mechanical ventilation. Pediatr Crit Care Med 2008;9(3): 270-277. 


\section{Respiratory Care Considerations in Childhood CANCER}

6. Duncan CN, Lehmann LE, Cheifetz IM, Greathouse K, Haight AE, Hall MW, et al. Clinical outcomes of children receiving intensive cardiopulmonary support during hematopoietic stem cell transplant. Pediatr Crit Care Med 2013;14(3):261-7.

7. Rowan CM, Gertz SJ, McArthur J, Fitzgerald JC, Nitu ME, Loomis A, et al. Invasive mechanical ventilation and mortality in pediatric hematopoietic stem cell transplantation: a multicenter study. Pediatr Crit Care Med 2016;17(4):294-302.

8. Acker SN, Linton J, Tan GM, Garrington TP, Bruny J, Hilden JM, et al. A multidisciplinary approach to the management of anterior mediastinal masses in children. J Pediatr Surg 2015;50(5):875-878.

9. Dishop MK, Kuruvilla S. Primary and metastatic lung tumors in the pediatric population: a review and 25-year experience at a large children's hospital. Arch Pathol Lab Med 2008;132(7):1079-1103.

10. Denbo JW, Zhu L, Srivastava D, Stokes DC, Srinivasan S, Hudson $\mathrm{MM}$, et al. Long-term pulmonary function after metastasectomy for childhood osteosarcoma: a report from the St Jude Lifetime Cohort Study. J Am Coll Surg 2014;219(2):265-271.

11. Elbahlawan L, Gaur AH, Furman W, Jeha S, Woods T, Norris A, Morrison RR. Severe H1N1-associated acute respiratory failure in immunocompromised children. Pediatr Blood Cancer 2011;57(4): 625-628.

12. Ison MG. Adenovirus in transplant recipients. Clin Infect Dis 2006; 43(3):331-339.

13. Waghmare A, Englund JA, Boeckh M. How I treat respiratory viral infections in the setting of intensive chemotherapy or hematopoietic cell transplantation. Blood 2016;127(22):2682-2692.

14. Srinivasan A, Wang C, Srivastava DK, Burnette K, Shenep JL, Leung W, Hayden RT. Timeline, epidemiology, and risk factors for bacterial, fungal, and viral infections in children and adolescents after allogeneic hematopoietic stem cell transplantation. Biol Blood Marrow Transplant 2013;19(1):94-101.

15. Elbahlawan LM, Morrison RR, Jeha S, Cheng C, Liu W, Fiser RT. Impact of neutrophil recovery on oxygenation in pediatric oncology patients with acute hypoxemic respiratory failure. J Pediatr Hematol Oncol 2011;33(7):e296-e299.

16. Lindemans CA, Leen AM, Boelens JJ. How I treat adenovirus in hematopoietic stem cell transplant recipients. Blood 2010;116(25): 5476-5485.

17. Patterson TF, Thompson GR 3rd, Denning DW, Fishman JA, Hadley $\mathrm{S}$, Herbrecht R, et al. Practice guidelines for the diagnosis and management of Aspergillosis: 2016 update by the Infectious Diseases Society of America. Clin Infect Dis 2016;63(4):e1-e60.

18. Nebiker CA, Lardinois D, Junker L, Gambazzi F, Matt P, Habicht $\mathrm{JM}$, et al. Lung resection in hematologic patients with pulmonary invasive fungal disease. Chest 2012;142(4):988-995.

19. Naeem F, Metzger ML, Arnold SR, Adderson EE. Distinguishing benign mediastinal masses from malignancy in a histoplasmosisendemic region. J Pediatr 2015;167(2):409-415.

20. Goss $\mathrm{CH}$. With every upside, there is a downside: chest radiation and suvivors of childhood cancers. Ann Am Thorac Soc 2016;13(9): 1448-1449.

21. Motosue MS, Zhu L, Srivastava, Stokes DC, Hudson MM, McPherson V, et al. Pulmonary function after whole lung irradiation in pediatric patients with solid malignancies. Cancer 2012;118(5):14501456.

22. Huang TT, Hudson MM, Stokes DC, Krasin MJ, Spunt SL, Ness KK. Pulmonary outcomes in survivors of childhood cancer: a systematic review. Chest 2011;140(4):881-901.

23. Josephson MB, Goldfarb SB. Pulmonary complications of childhood cancers. Expert Rev Respir Med 2014;8(5):561-571.

24. Inaba H, Yang J, Pan J, Stokes DC, Krasin MJ, Srinivasan A, et al. Pulmonary dysfunction in survivors of childhood hematologic ma- lignancies after allogeneic hematopoietic stem cell transplantation. Cancer 2010;116(8):2020-2030.

25. Children's Oncology Group (COG): Long-term follow-up guidelines for survivors of childhood, adolescent, and young adult cancers. http://survivorshipguidelines.org. Accessed April 4, 2017.

26. Hudson MM, Ness KK, Gurney JG, Mulrooney DA, Chemaitilly, W, Krull KR, et al. Clinical ascertainment of health outcomes among adults treated for childhood cancer. JAMA 2013;309(22):2371-2381.

27. Green DM, Zhu L, Wang M, Ness KK, Krasin MJ, Bhakta NH, et al. Pulmonary function after treatment for childhood cancer: a report from the St Jude Lifetime Cohort Study (SJLIFE). Ann Am Thorac Soc 2016;13(9):1575-1585.

28. Fulgoni P, Zoia MC, Corsico A, Beccaria M, Georgiani G, Bossi G, Cerveri I. Lung function in survivors of childhood acute lymphoblastic leukemia. Chest 1999;116(5):1163-1167.

29. Green DM, Merchant TE, Billups CA, Stokes DC, Broniscer A, Bartels U, et al. Pulmonary function after treatment for embryonal brain tumors on SJMB03 that included craniospinal irradiation. Int J Radiat Oncol Biol Phys 2015;93(1):47-53.

30. Armstrong GT, Joshi VM, Zhu L, Srivastava D, Zhang N, Ness KK, et al. Increased tricuspid regurgitant jet velocity by Doppler echocardiography in adult survivors of childhood cancer: a report from the St Jude Lifetime Cohort Study. J Clin Oncol 2013;31(6):774-781.

31. Huang TT and Ness KK. Exercise interventions in children with cancer: a review. Int J Pediatr 2011;2011:461512.

32. Ness KK, Gurney JG, Zeltzer LK, Leisenring W, Mulrooney DA, Nathan PC, et al. The impact of limitations in physical, executive, and emotional function on health-related quality of life among adult survivors of childhood cancer: a report from the Childhood Cancer Survivor Study. Arch Phys Med Rehabil 2008;89(1):128-136.

33. Srinivasan A, Srinivasan S, Sunthankar S, Sunkara A, Kang G, Stokes DC, Leung W. Pre-hematopoietic stem cell transplant lung function and pulmonary complications in children. Ann Am Thorac Soc 2014; 11(10):1576-1585

34. Sakaguchi H, Takahashi Y, Watanabe N, Doisaki S, Muramatsu H, Hama A, et al. Incidence, clinical features, and risk factors of idiopathic pneumonia sydnrome following hematopoietic stem cell transplantation in children. Pediatr Blood Cancer 2012;58(5):780-784.

35. Heggen J, West C, Olson E, Olson T, Teague G, Fortenberry J, Yeager AM. Diffuse alveolar hemorrhage in pediatric hematopoietic cell transplant patients. Pediatrics 2002;109(5):965-971.

36. Richardson PG, Ho VT, Giralt S, Arai S, Mineishi S, Cutler C, et al. Safety and efficacy of defibrotide for the treatment of severe hepatic veno-occlusive disease. Ther Adv Hematol 2012;3(4):253-265.

37. Barker AF, Bergeron A, Rom WN, Hertz MI. Obliterative bronchiolitis. N Engl J Med 2014;370(19):1820-1828.

38. Gazourian L, Rogers AJ, Ibanga R, Weinhouse, GL, Pinto-Plata V, Ritz J, et al. Factors associated with bronchiolitis obliterans syndrome and chronic graft-verus-host disease after allogeneic hematopoietic cell transplantation. Am J Hematol 2014;89(4):404-409.

39. Cordier JF. Cryptogenic organizing pneumonia. Eur Respir J 2006; 28(2):422-446.

40. Inaba H, Jenkins JJ, McCarville MB, Morrison RR, Howard SC, Pui $\mathrm{CH}$, Ribeiro RC. Pulmonary alveolar proteinosis in pediatric leukemia. Pediatr Blood Cancer 2008;51(1):66-70.

41. Norman BC, Jacobsohn DA, Williams KM, Au B, Au MA, Lee SJ, et al. Fluticasone, azithromycin, and montelukast (FAM) therapy in reducing corticosteroid exposure in bronchiolitis obliterans syndrome after allogeneic hematopoietic stem cell transplant: a case series of eight patients. Bone Marrow Transplant 2011;46(10):1369-1373.

42. Larcombe PJ, Kapur N, Fraser CJ, Coulthard MG, Schlapbach LJ. Intrabronchial administration of activated recombinant Factor VII in a young child with diffuse alveolar hemorrhage. Pediatr Blood Cancer 2014;61(3):570-571. 


\section{Respiratory Care Considerations in Childhood Cancer}

43. Shah DP, Ghantoji SS, Shah JN, El Taoum KK, Jiang Y, Popat U, et al. Impact of aerosolized ribavirin on mortality in 280 allogeneic haematopoietic stem cell transplant recipients with respiratory syncytial virus infections. J Antimicrob Chemother 2013;68(8):1872-1880.

44. Pancera CF, Hayashi M, Fregnani JH, Negri EM, Deheinzelin D, de Camargo B. Noninvasive ventilation in immunocompromised pediatric patients: eight years of experience in a pediatric oncology intensive care unit. J Pediatr Hematol Oncol 2008;30(7):533-538.

45. Shah PS, Ohlsson A, Shah JP. Continuous negative extrathoracic pressure or continuous positive airway pressure compared to conventional ventilation for acute hypoxaemic respiratory failure in children. Cochrane Database Syst Rev 2013;(11):CD003699.
46. Elbahlawan L, Srinivasan A, Morrison RR. A critical care and transplantation-based approach to acute respiratory failure after hematopoietic stem cell transplantation in children. Biol Blood Marrow Transplant 2016;22(4):617-626.

47. Sterni LM, Collaco, JM, Baker CD, Carroll JL, Sharma GD, Brozek JL, et al. An official American Thoracic Society Clinical Practice Guideline: pediatric chronic home invasive ventilation. Am J Respir Crit Care Med 2016;193(8):e16-e35.

48. Yousef S, Benden C, Boyer D, Elidemir O, Frischer T, Goldfarb S, et al. Lung transplantation in children following bone marrow transplantation: a multi-center experience. Pediatr Transplant 2013;17(3): 231-236.

\section{Discussion}

Sweet: Thanks, that was a great overview. I don't know this field very well, but with obliterative bronchiolitis after a stem cell transplant, have people looked for the same risk factors that we're starting to see with lung transplant, such as autoantibodies and human leukocyte antigen antibodies?

Stokes: Some similar work has been identified in the hematopoietic stem cell transplantation (HSCT) population, but I'm not very familiar with that literature. ${ }^{1}$ We tend to see them later when they present. FAM therapy-fluticasone, azithromycin, and montelukast-is the newest therapy for which some data are available but with limited pediatric experience. ${ }^{2}$ There is so much work that needs to be done in this area.

Panitch: I took care of a young man from childhood through early adulthood who had had a Wilms' tumor. He had a tiny chest with normal lungs by $\mathrm{CT}$ imaging and an FVC of about $40 \%$ predicted. I noticed in your talk that chest-wall growth abnormalities have been identified as a long-term issue, so I was wondering if anyone is thinking about expansion surgeries, especially for children who receive their damaging therapies early in life, and you can follow their chest-wall growth? Is there a role for thoracic expansion surgery to improve lung function in those patients?
Stokes: I'm not aware of anybody doing that, but it's a really interesting question. Identifying this group early enough to make an intervention worthwhile would be essential to that. Again, I think some of the worst abnormalities of the chest wall were related to older regimens of radiation therapies. I think they've become better at targeting where they need to target, so we don't see the gross chest-wall deformities that we used to see back in the "80s. What to do with that group, I'm not sure anybody has thought about using chest expansion.

Panitch: Just as a follow-up, have you looked at or measured chest-wall compliance in the children who have required repeated thoracic interventions?

Stokes: Do you know how to do that, Howard? Because nobody remembers anymore how to drop esophageal balloons and measure chest-wall compliance except for us old-timers. We actually have some data from the St Jude LIFE study ${ }^{3}$ that Dr Kirsten Ness has collected looking at restriction in chest-wall expansion and relating it to functional changes. There just isn't that much about the mechanics of the chest wall. When oncologists see a restrictive defect, they see the lung and assume it's pulmonary fibrosis. But I think one of the things we bring to this area is thinking more broadly about diaphragm, chest-wall, and respiratory muscles that could influence restrictive change, not just fibrosis. I'll also mention that we have a new spe- cial interest group on pulmonary complications of childhood cancer therapy in the American Thoracic Society, and if you or anybody in your group is interested in pulmonary complications and late effects, we would love to have more members who have an interest in this area. I think it's a great area for research for the next 20 years.

Smallwood: This might be perhaps stretching too far into the future, but I recall a group of researchers at Northeastern University who published a study ${ }^{4}$ in Science Translational Medicine. What was interesting to me was the intervention in an animal model of an oncologic process was supplying $40-60 \% \quad \mathrm{O}_{2}$. They demonstrated in their cohort of mice that they could awaken anti-tumor T lymphocyte cells just by using inhaled $\mathrm{O}_{2}$. Essentially, breathing in high concentrations of oxygen helped to fight cancer. Although it's translational at this point, do you have any thoughts?

Stokes: Unfortunately, we do a lot of $\mathrm{O}_{2}$ therapy, but it's usually for the wrong reasons in the ICU and not for its potential antitumor effects. Ira [Cheifetz], I know the PALISI (Pediatric Acute Lung Injury and Sepsis Investigator) group has looked at bone marrow transplant and done a lot of nice work trying to tease out the more acute complications and how to manage that better.

Cheifetz: You provided an excellent summary, thank you. Most of the work by the stem cell transplant subgroup 


\section{Respiratory Care Considerations in Childhood Cancer}

of the PALISI Network ${ }^{5}$ has investigated acute complications; we have not done as much work on long-term effects. ${ }^{6}$ The one thing I would like to mention, and I am sorry if I missed it, is diffuse alveolar hemorrhage. This is one of the important clinical entities that we still wrestle with in the ICU. We saw one child recently who, out of nowhere, had a catastrophic pulmonary bleed. As much as we have tried over the years to figure out the right recipe of therapies, both ventilator and non-ventilatory, we still struggle with this population. Kyle [Rehder] has quite a bit of experience with this population, and I would be curious to hear his thoughts as well.

Stokes: I did include DAH in the paper, but one of the therapies that respiratory therapists might be involved with is use of nebulized factor VII. I don't know if you have tried that in any cases? There are limited case series in pediatrics, and we've been asked a number of times to directly instill factor VII in patients with diffuse alveolar hemorrhage at bronchoscopy. It's definitely an area where the outcome is terrible, and that's about all you can say. It tends to come in runs, and we get these runs of DAH, and when we ask the transplant people what they're doing differently, they don't know. But it has a bad outcome, particularly if it's associated with an underlying infection.

Rehder: That was my sense as well from our population. We have tried nebulized factor VII, but with concerns that we would form a large obstructive clot in the airways and then have a new issue. The patient tolerated the nebulized factor VII, but as you stated, it was a rescue therapy in a patient with a very poor prognosis, and the patient did not ultimately survive. And we've tried systemic factor VII as well in the setting of alveolar hemorrhage, but it seems like it comes down to what is the underlying reason for the bleed, and if it's infection, it often feels like we can't get on top of it.

Stokes: The reference in the paper is one of the most recent case reports. You probably saw it, and it was exactly like you said, a pediatric patient who they gave factor VII to and developed a clot in the endotracheal tube and acutely decompensated, and the tube had to be taken out emergently. That's something people need to be aware of, that this is not a therapy without potential downsides.

\section{REFERENCES}

1. Barker AF, Bergeron A, Rom WN, Hertz M. Obliterative bronchiolitis N Engl J Med 2014; 370(19):1820-1828.

2. Williams KM, Cheng GS, Pusic I, Jagasia M, Burns L, Ho VT, et al. Fluticasone, azithromycin, and montelukast treatment for new-onset bronchiolitis obliterans syndrome after hematopoietic cell transplantation. Biol Blood Marrow Transplant 2016;22(4):710716.

3. Green DM, Zhu L, Wang M, Ness KK, Krasin MJ, Bhakta NH, et al. Pulmonary function after treatment for childhood cancer: a report from the St Jude Lifetime Cohort Study (SJLIFE). Ann Am Thorac Soc 2016;13(9): 1575-1585.

4. Hatfield SM, Kjaergaard J, Lukashev D, Schreiber TH, Belikoff B, Abbott R, et al. Immunological mechanisms of the antitumor effects of supplemental oxygenation. Sci Transl Med 2015;7(277):277ra30-

5. Duncan CN, Lehmann LE, Cheifetz IM, Greathouse K, Haight AE, Hall MW, et al. Clinical outcomes of children receiving intensive cardiopulmonary support during hematopoietic stem cell transplant. Pediatr Crit Care Med 2013;14(3):261-267.

6. Rowan CM, Gertz SJ, McArthur J, Fitzgerald JC, Nitu ME, Loomis A, et al. Invasive mechanical ventilation and mortality in pediatric hematopoietic stem cell transplantation: a multicenter study. Pediatr Crit Care Med 2016;17(4):294-302. 